\title{
Китайские электронные компоненты и российский рынок: специфика и возможности
}

Еще совсем недавно казалось, что электронные компоненты из Китая, как и многие другие виды продукции, произведенной в этой стране, обладают только одним преимуществом - низкой ценой. Их качество и технический уровень априори вызывали сомнение. Сегодня Китай достиг больших высот во многих областях науки и техники, китайские компании занимают лидирующие позиции на телекоммуникационном рынке, на рынке абонентских устройств, в информационных технологиях, в стране стремительно развивается кристальное производство.

Наша редакция совместно с выставкой ExpoElectronica решила узнать у представителей компаний, в число которых вошли дистрибьюторы электронных компонентов, российский производитель электронных устройств, а также китайская компания, продукция которой представлена на российском рынке, их мнение о том, что сейчас представляют собой китайские электронные компоненты, насколько они востребованы на российском рынке и какие проблемы в работе с китайскими производителями уже не актуальны, а какие еще до конца не решены.

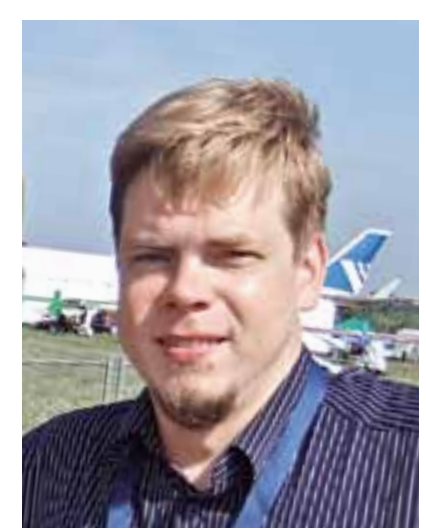

заться от произведенных за рубежом компонентов и технологий единовременно невозможно. Потребуется пять, а может быть, десять и более лет постепенного перехода на отечественную элементную базу с одновременным повышением ее конкурентных преимуществ.

Компромиссным вариантом грядущих изменений может быть продукция КНР, изготовленная как коммерческими компаниями, так и государственными институтами структуры CETC (China Electronics Technology Group Corporation) и др. Китайские компоненты отличаются достаточно высокими для многих вариантов применения характеристиками, а их что российская электронная промышленность не должна зависеть от западных компанийпроизводителей ввиду перемени стратегических интересов России. Речь идет о компонентах из США, Европы, а также Японии (условно отнесенной к Западу). Тем не менее, полностью отка-
Георгий Кон, ведущий менеджер по продукции направления «ВЧ / СВЧ-компоненты» группы компаний «Макро Групп» конкурентоспособность повышается, вплотную приближаясь к аналогам из США, Европы и Японии.

Входящие в структуру СЕТС компании владеют всеми необходимыми российскому рынку технологиями, такими как, например, 0,15 и 0,1 мкм GaN HEMT.

Потребность в этих и других компонентах растет из года в год, что обусловлено прежде всего отсутствием любых экспортных ограничений на поставки в Россию.

Впечатляет динамика развития китайской продукции, в частности СВЧ-электроники. Во времена СССР мы помогали организовывать многие производства в Китае, вплоть до строительства отдельных цехов по выпуску полупроводниковых компонентов (например, СЕTС29, в Чэнгду). В 2000-х годах их продукция начала продаваться на экспорт, но отставала даже от российской по характеристикам и была значительно дороже. В 2020 году СВЧ-компоненты производства NEDItek, Metda и SIWI уже конкурируют с западными аналогами, при этом, в отличие от многих российских изделий, выпускаются серийно, большими объемами. 
Одновременно со снижением цены китайцам удалось значительно повысить процент выхода годных изделий, что благоприятно отражается на динамике уменьшения количества претензий к качеству продукции. За последние пять лет в нашей компании не было ни одного случая критического для заказчика несоответствия заявленных характеристик фактическим, равно как и не возникало вопросов к их надежности.

Ключевой особенностью, а можно сказать, проблемой продукции КНР (прежде всего произведенной государственными институтами) является ограниченный объем предоставляемой технической документации на продукт. Нельзя утверждать, что это касается всех компонентов, но тенденция заметная. Например, при отсутствии необходимого графика или некоторых данных в документации российский разработчик должен обратиться к дистрибьютору, который в минимальные сроки предоставит всю необходимую информацию. Но, к сожалению, условная скупость исходной документации часто заставляет многие компании и разработчиков отказываться от продукции производителя.

Справедливости ради следует отметить, что большая часть компонентов сопровождается достаточным количеством данных для принятия решения об их использовании. Тем не менее ряд параметров иногда приходится дополнительно уточнять у разработчиков и при необходимости проводить требуемые замеры и тесты силами производителя.

Для китайских заказчиков, в отличие от российских, веб-сайт производителя, полнота документации, известность вендора имеют второстепенное значение. Китайский заказчик связывается с производителем и приезжает к нему на фабрику. В личной беседе все вопросы снимаются, заказчик лично проверяет производителя. В Поднебесной это бизнес, основанный на отношениях, а не на фактах, объективно предоставляемых из различных независимых источников. В этом принципиальное отличие менталитета российского заказчика от его китайского коллеги. Наша задача - максимально сгладить этот барьер, установить взаимодействие и расположить к себе заказчика, сконцентрировать внимание производителя на проекте.

Все дополнительные сервисы, в частности поставка бесплатных образцов, отладочных плат и т.п., предоставляются и китайскими фабриками. Проблем с минимальной партией заказываемого товара, как правило, не существует, так как китайские производители нацелены преимущественно на замещение у себя на рынке трудно поставляемых в Китай позиций, а значит, прежде всего дорогостоящих и уникальных. Высокое же значение минимального количества заказываемых микросхем требуется для относительно недорогих, массовых компонентов, которые свободно поставляются компаниями США и в Китай, и в Россию.

Что касается сроков поставок, то здесь всё неоднозначно. В связи с санкциями США в отношении лидера телекоммуникационного рынка КНР, компании Huawei, их производство вынуждено было срочно искать замену элементной базы среди местных поставщиков. Из-за больших объемов временно увеличивался срок поставки. Но ситуация меняется, к сегодняшнему дню сроки поставок сокращаются, и многие компоненты поставляются уже своевременно.

Наша компания работает со многими китайскими производителями. В 2019 году на выставке ExpoElectronica в Москве у нас были совместные стенды с компаниями Elite (СВЧ- и ИК-компоненты) (КНР) и Oupiin (разъемы) (Тайвань). Конечно, сохраняется определенное недоверие российских клиентов к китайской продукции. Свою задачу мы видим в том, чтобы преодолеть настороженность, для этого отмечаем преимущества данной продукции и делимся опытом ее поставки на российский рынок. У многих словосочетание made in China пока еще прочно ассоциируется с недостаточно высоким качеством и низкой ценой, но не c hi-tech и, к сожалению, не с ответственностью китайского производителя и поддержкой им купленного продукта. Но времена меняются, и наша задача, как дистрибьютора, установить прямую и оперативную связь между заказчиком и производителем для решения возможных проблем.

Мы не меняем производителей, годами работаем с проверенными вендорами. Тем самым подчеркивается наш ответственный подход к каждому проекту.

При работе с китайскими компаниями, конечно, существует проблема языкового барьера, которая касается прежде всего технических вопросов, не раскрытых в документации. Мы обеспечиваем оперативную поддержку и при необходимости устраиваем прямой конференц-звонок, связывая заказчика с производителем. В отдельных случаях предусмотрена возможность визита к поставщику продукции. 


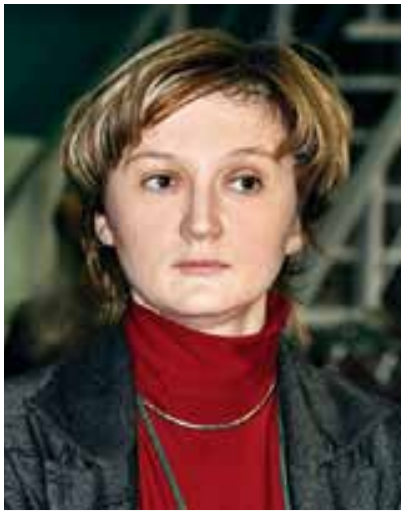

Сегодня китайские производители электронных компонентов широко представлены на российском рынке. В дистрибьюторскую линейку практически каждого крупного поставщика электронной продукции в России входят китайские бренды. Востребованность китайских диодов, резисторов, переключателей не вызывает сомнения, особенно в тех областях применения, где ценовая категория при достойном качестве важнее долговременной стабильности.

Китайская продукция в области ЭКБ, представленная на рынке, за последние годы очень изменилась: все чаще предлагаются не пассивные компоненты, а микросхемы, транзисторы и модули собственной разработки. В программе поставок нашей компании - бренды НТС Таејіng Korea, SG Micro, BPS, Ebyte, Espressif, Netsol и др. Бизнес-модели таких предприятий примерно одинаковые: инженерные центры находятся в Южной Корее, производственные мощности в Китае. Офисы многих компаний расположены в США.

В фокусе интересов таких производств находятся популярные линейки микросхем для управления питанием, светодиодами, полевые транзисторы общего применения. Качество выпускаемой продукции очень высокое, об этом говорит тот факт, что некоторые глобальные дистрибьюторы включают данные бренды в свои линейки поставок.

\section{дела маркетинга 000 «Платан»}

следует отметить особенности работы с китайскими производителями, их отличия от производителей из Европы и США

Во-первых, отношение российских производителей электроники к китайской продукции двоякое. Компоненты широкого спектра применения не вызывают опасений, а внедрение микросхем и транзисторов в отечественные разработки затруднено. У одних производителей это связано с долгими циклами тестирования и согласований, у других - с нежеланием что-либо менять, пока, например, на рынке доступны оригиналы ТІ.

Во-вторых, широкому внедрению китайских компонентов в отечественные разработки препятствует отсутствие полной технической документации. С одной стороны, крупные производители выпускают каталоги, предоставляют листы технических данных (datasheet) и сертификаты, но зачастую они бывают неполными и недостаточными для отечественных разработчиков. С другой стороны, это компенсируется доступностью образцов, возможностью разместить пробный заказ или вернуть товар. Дополнительное преимущество - срок производства и поставки комплектующих, как правило, не более четырех-шести недель при поставке напрямую с завода.

Трудности внедрения полупроводниковых компонентов китайских компаний на российском рынке мы считаем издержками «переходного периода". В скором времени крупные китайские производители микросхем и транзисторов займут часть рынка, принадлежащего таким мировым гигантам, как TI, On Semi, NXP и др.

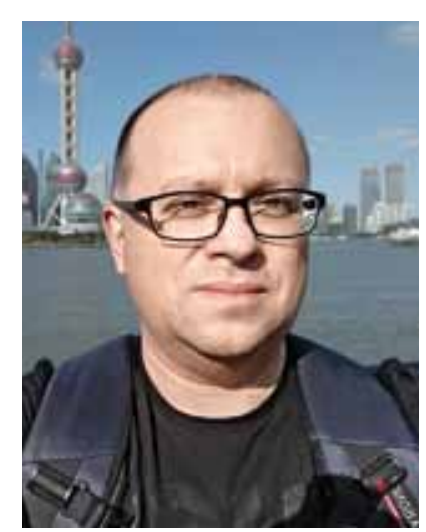

Сергей Гущин, ведущий специали За последние годы тема дистрибуции компонентов китайского производства неоднократно поднималась в нашей компании. Видя растущий интерес со стороны заказчиков и предложения китайских производителей, мы приняли решение развивать это направление системно. Наибольшее внимание было уделено тем областям из перечня поставок нашей компании, которые были недостаточно широко представлены традиционными европейскими и американскими производителями. ист по продажам группы компаний «Симметрон»

Сегодня с учетом динамики спроса можно говорить об определенном сдвиге (на рынке и в сознании разработчиков) в отношении заказчиков - производственных компаний к продукции китайских поставщиков. Особенно это проявляется в сегменте проектных заказчиков, конкурирующих в своих областях с китайскими производителями. Как показали результаты тестирования на стороне заказчиков, качество силовых дискретных компонентов - на уровне традиционных брендов, а характеристики соответствуют заявленным в документации. С техдокументацией до сих пор возникают проблемы в плане ее полноты, содержания и перевода, что вызывает определенные сложности. В то же 
время весьма заметное преимущество для заказчиков - значительно меньшие сроки поставки и разница в стоимости на уровне 20-30\%.

Группа компаний “Симметрон» - официальный дистрибьютор нескольких китайских производителей компонентов и модулей по таким направлениям, как силовые MOSFET, память различного типа, модули беспроводной связи. Для проектной работы предоставляется техническая поддержка, образцы и документация. Наиболее ходовые позиции доступны со склада. На выставке ExpoElectronica 2020 в Москве будет демонстрироваться вся номенклатура продукции китайских производителей, представляемых нашей компанией. Мы тщательно подходим к выбору и проверке партнеров из Китая. Компании, с которыми развивается сотрудничество, - крупные производственные предприятия, известные на рынке более 15 лет. Многим из них обеспечивается государственная поддержка, в частности посредством долевого участия.

Вся деловая переписка, документальная часть и переговоры ведутся нами на английском языке. Нет проблем коммуникации, если не считать разницу во времени. До начала работы мы посетили предприятия в Китае, а китайские региональные представители регулярно бывают с нами у наших заказчиков в России. Наметившийся кризис на рынке компонентов стимулирует развитие дополнительных направлений дистрибуции и дает шанс новым поставщикам Дальнейшее расширение сотрудничества с китайскими производителями является для нас приоритетной задачей.

\section{Николай Дмитриев, руководитель отдела закупок НПО «СтарЛайн»}

нПО «СтарЛайн» - лидер российского рынка автобезопасности с компетенциями в области автоматизации, роботизации, телематики и разработки технологий беспилотного вождения. Компания выполняет контрактные заказы любого уровня сложности в сфере производства электроники, пресс-форм, литья изделий из пластмасс, кабельной сборки и других сегментах. Приоритетом НПО "СтарЛайн» в работе с поставщиками является стабильное в длительном периоде качество, подтвержденное устойчивыми технологическими процессами. Компания ориентируется на технологии мирового уровня и предъявляет одинаковые требования ко всем производителям, будь то китайские, российские или европейские. НПО "СтарЛайн» представляет крупносерийное производство, поэтому важно убедиться в том, что предприятие может не только изготовить качественные образцы изделий, но и обеспечить стабильное качество большого объема продукции. Для этого необходим постоянный аудит предприятий, даже если это известный во всем мире бренд.

Основная проблема китайских производителей электронных компонентов - плохая техническая документация. При ее оформлении предприятия из Китая не всегда соблюдают нормы, принятые в мире. Это может усложнить выбор элементной базы. Приходится запрашивать результаты тестов, рекомендации по применению и прочие документы, которые европейские и американские производители предоставляют на сайте. Локальные китайские производители, малоизвестные в мире, оформляют документацию только на китайском языке, переводить ее на русский или английский достаточно сложно. Требуется время на уточнение технических характеристик.

Важно отслеживать качество материалов и заключать с производителем договоры с жесткими мерами ответственности. Если предприятие допустит отклонение в технологическом процессе, оно должно нести материальную ответственность. Это касается любых производителей, не только китайских. Мы рекомендуем съездить на производство и посмотреть, какие нормы контроля качества приняты, какое оборудование используется, как работают с несоответствующей продукцией. И только потом принимать решение работать с производителем или нет.

Есть продукция, которую китайские производители электронных компонентов хорошо освоили и сейчас выходят с ней на международный рынок. Это пассивные компоненты, беспроводные модули, разъемы и электромеханика, соединители для электроники. По этим продуктам они конкурируют с европейскими и американскими поставщиками. Однако сложную электронику китайцы еще продолжают осваивать.

Отметим, что производители из Китая всегда ориентированы на своих клиентов. Не бывает 
проблем с отправкой пробных образцов, наборов для отладки и изготовления специальных продуктов. Даже если требуется замена разъема или дискретного диода, они сами проводят подбор и могут выполнить изделие под заказ, при этом стоимость оснастки будет включена в стоимость товара. Производители из других стран зачастую выставляют отдельный счет за оснастку, что накладывает некоторые ограничения на сотрудничество. Образцы изделий могут не пройти тесты, или большая партия продукции не пойдет в производство, поэтому заказчик не всегда готов заплатить за оснастку. Китайские производители более клиентоориентированы и готовы идти навстречу.

С точки зрения языкового барьера проблем с китайскими компаниями не возникает. у крупных производителей, которые работают на мировом рынке, есть отдел продаж и техническая поддержка на английском языке. Даже небольшие нишевые производители, преимущественно говорящие по-китайски, имеют в штате менеджера, свободно говорящего по-английски. А крупные китайские производители, которые сотрудничают с русскими компаниями, нанимают русскоговорящих специалистов.

При отлаженной логистике предприятия из Китая соблюдают сроки производства и поставки компонентов. В целом, при должном контроле и аудите китайские производители электронных компонентов являются надежными, хорошими поставщиками и заслуживают место на рынке.

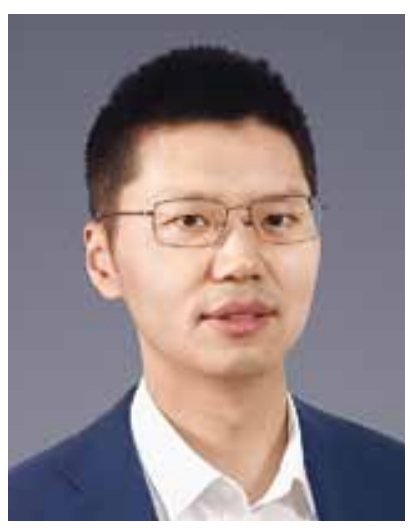

нах можно назвать перспекТивн тизацию, альтернативные источники энергии, передовое производство. И в этих отраслях одинаково востребованы новые технологии, новая продукция. Иными словами, можно сказать, что потребности наших рынков одинаковы. Это позволяет нам поставлять на российский рынок наши успешные и экономически эффективные решения и услуги.

Но существуют и различия. Прежде всего, определенно, это объем рынка. Также существует разница в том, какие секторы в этих двух странах более крупные. Но поскольку мы ставим перед собой цель создавать качественные и надежные изделия, а в России наиболее востребованными являются решения для промышленной электроники и телекоммуникаций, то есть для областей, в которых основное внимание уделяется качеству и надежности, российский рынок очень хорош для нас.

Компания Mornsun участвует в московской выставке ExpoElectronica уже более 10 лет.
ExpoElectronica проводится ежегодно в течение 23 лет и является самой крупной выставкой электронной и радиоэлектронной промышленности в России и Восточной Европе. Участие в этом мероприятии - очень мощная маркетинговая акция для Mornsun на российском рынке, помогающая усилить узнаваемость нашего бренда, показать отрасли нашу новейшую продукцию и решения, выстроить отношения с новыми клиентами и углубить взаимодействие с существующими заказчиками. Кроме того, это - эффективный способ для китайской компании познакомиться с российскими отраслевыми трендами и узнать ценную для нас информацию.

В этом году мы представим российскому рынку нашу новейшую линейку продукции - импульсные блоки питания мощностью 35-350 Вт в корпусе. Это семейство содержит широкий ассортимент изделий, прошедших все необходимые испытания на ЭМС, обладающих функциями защиты и высоким КПД, что делает их отличным выбором для широкого круга применений, включая управление промышленными процессами и промышленную автоматизацию, машины и оборудование, интеллектуальную безопасность, «умные электросети», Интернет вещей, механическое и электрическое оборудование, электронные приборы, “умные здания» и бытовую технику.

Усиление позиций Mornsun на российском рынке вместе с лидерами локального рынка электроники - стратегия нашей компании. 
В настоящее время у нас есть три замечательных партнера - «ЭКО Роwer», «Компэл», «МикроэМ», которые помогают нам работать на благо наших клиентов в России

Mornsun обладает сильными возможностями в области разработки, экономически эффективной продукцией и способностями по автоматизации, но мы не в полной мере обладаем компетенциями в отношении продаж в России. Однако наши партнеры - хорошо известные дистрибьюторы электронных компонентов в России с полноценной сетью продаж, профессиональной маркетинговой командой, сильными инженерами по применению и отлаженной логистической системой. Мы уверены, что плотное сотрудничество между нами - хорошее решение, обеспечивающее взаимное дополнение наших возможностей. Это сочетание высококачественной продукции и технической поддержки Mornsun, включающих кастомизацию, специализированные разработки для конкретных применений, решения в области систем распределения электропитания, с локальной российской платформой профессионального сервиса, направленное на более комплексное обслуживание клиентов в отношении продукции и технологий.

Для предприятия жизненно важным аспектом является качество его продукции. Результатом 20 лет упорных усилий Mornsun стали большие достижения в области разработки, автоматизации, системного управления, благодаря которым обеспечивается высокое качество изделий.

В компании установлены всеобъемлющие стандарты продукции, охватывающие все стадии - от разработки и производства до контроля и клиентского сервиса. Проектирование строго контролируется в соответствии с процессом IPD (Integrated Product Development комплексная разработка изделий), проводятся жесткие испытания на надежность. Для обеспечения постоянного улучшения и высокой надежности изделий в компании применяются строгая система оценки поставщиков, входной контроль качества комплектующих и материалов, а также выходной контроль. Кроме того, уровень автоматизации производства до 60\% позволил Mornsun достичь действительно выдающейся стабильности качества и надежности продукции.

С моей точки зрения, больше и больше китайских производителей все в большей мере делают упор на повышение качества изделий. Хотя такого нельзя сказать про всех без исключения китайских производителей, отрасль электронных компонентов Китая в целом за последние десятилетия определенно сделала большой шаг вперед.

Наша компания производит различные высококачественные изделия, включая AC/DC- и DC/DC-преобразователи, импульсные блоки питания в корпусе, адаптеры, развязывающие усилители, драйверы Бтиз и светодиодных устройств, ИС, трансформаторы и другие, бо́льшая часть которых имеет сертификаты UL, CE, CSA, CB и DOE Level VI. Кроме того, у нас есть своя собственная лаборатория, построенная в соответствии со стандартом ISO 17025 и одобренная такими организациями, как UL, CSA, TÜV, DEMKO, поэтому мы сами можем выпускать протоколы испытаний и сертификаты CE, UL, CB.

Мы предоставляем сертификаты, протоколы испытаний и техническую документацию на все наши изделия на английском языке. Заказчики могут скачать их на сайте или получить их, связавшись с нашим подразделением продаж.

Помимо более чем 5 тыс. стандартных продуктов, мы предлагаем и кастомизированные решения и стремимся оказывать такие услуги заказчикам по всему миру, включая Россию. Каждый год мы работаем с нашими клиентами по множеству проектов, с тем чтобы удовлетворить их конкретные требования. Компания Mornsun в своем бизнесе всегда следовала философии, ориентированной на клиента, и старалась предоставлять всем своим заказчикам наилучший сервис.

Существуют ли сложности в работе с российским рынком, вызванные языковым барьером? Конечно, языковой барьер существует при любой международной деятельности, но для нас это не проблема. У нас есть не только локальные дистрибьюторы с сотрудниками, для которых русский язык родной и которые владеют также английским языком. У нас есть и собственные сотрудники, которые могут говорить и на русском, и на английском языках. Все они могут свободно обсуждать с заказчиками те или иные детали, решать необходимые вопросы и передавать информацию от клиентов без потерь и ошибок. Кроме того, мы проводим в России технические семинары как онлайн, так и офлайн.

материал подготовлен И. В. Кокоревой и Ю. С. Ковапевским 